\title{
CONCILIAÇÃO: ANÁLISE DA AUDIÊNCIA PRELIMINAR COMO INSTRUMENTO DE CELERIDADE E EFETIVIDADE DA PRESTAÇÃO JURISDICIONAL
}

Stella Beatriz do Carmo

Estudante do $4^{\circ}$ ano de Direito da Faculdade de Direito de Franca e bolsista do CEPIC da mesma instituição

stellabia@hotmail.com

\section{RESUMO}

O presente artigo traz no seu bojo uma discussão acerca das alterações das Leis $\mathrm{n}^{0}$ 8.952/94 e 10.444/02, que introduziram diversas modificações no Código de Processo Civil, em especial, a criação de uma audiência preliminar, antes da audiência de instrução e julgamento, buscando principalmente a conciliação entre as partes, pondo fim ao litígio e garantindo a satisfação dos interesses das partes, evitando assim, o desgaste sofrido pelos litigantes com o trâmite do processo. Após uma análise histórica da evolução do instituto da conciliação no ordenamento jurídico brasileiro, passa-se a um estudo dos objetivos e finalidades da audiência preliminar, bem como à demonstração do pensamento de diversos doutrinadores acerca do instituto da audiência preliminar como instrumento efetivo de celeridade e efetividade da prestação jurisdicional, bem como os motivos pelos quais nem sempre a audiência prevista no artigo 331, tem alcançado o objetivo precípuo do legislador reformista: a simplificação do feito e resposta rápida aos anseios sociais. Será apresentada também, outras maneiras de composição amigável dos litígios, que não a judicial, que podem ser obtidas através da mediação e da arbitragem.

Palavras chave: audiência preliminar, conciliação, celeridade processual.

\section{ABSTRACT}

Title: Conciliation: The Analysis of the Preliminary Hearing as an Instrument of Swiftness and Effectiveness of the Jurisdictional Procedure.

The present chapter brings in its core a discussion about the changes in Laws No 8.952/94 and 10.444/02, which introduced several alterations to the Civil Code Practice. It focuses on the creation of a preliminary hearing, before the pre-trial review, which searches for the conciliation between the parties, putting an end to litigation, and making sure both parties' interests are safeguarded. By doing so, the weariness suffered by the litigants throughout the course of the legal proceedings may be avoided. After a historical analysis of the evolution of the institution of the conciliation in the Brazilian juridical system, the next step is to study the purposes and aims of the preliminary hearing, as well as to demonstrate the thinking of several doctrinarians in relation to the institution the of preliminary hearing as an effective instrument of swiftness and effectiveness when there's a jurisdictional procedure. Also, the reasons why the hearing, anticipated in chapter 331, hasn't always reached the reform legislator's primordial purpose: a simplification of the procedure and a quick response to social anxiety will be studied. Moreover, other ways of amicable settlement of litigations 
(other than the judicial one) that might be obtained through mediation and arbitration, will be presented.

Key-words: Preliminary hearing, Conciliation and Swiftness Procedure 1. Introdução

A reforma processual introduzida pela Lei no 8.952/94, dando nova redação ao artigo 331 do Código de Processo Civil e instituindo como um dos deveres basilares do juiz, tentar, a qualquer tempo, conciliar as partes (art 125, IV, CPC), bem como, diversos outros dispositivos no CPC (arts 447 a 449, 599), a Lei dos Juizados Especiais (Lei nº 9.099/95) e até mesmo a lei especial da arbitragem (Lei $n^{\circ}$ 9.307/96), prestigiaram a tentativa de resolução dos conflitos através de meios alternativos, mostrando assim, a preocupação do legislador brasileiro com a rápida solução dos problemas jurídicos, garantindo aos jurisdicionados a máxima celeridade e efetiva prestação jurisdicional, tão aclamados nos tempos atuais.

A audiência preliminar prevista no art. 331 do CPC propõe a valorização da conciliação entre as partes, como expressão máxima do principio da oralidade, proporcionando maior agilidade à realização da Justiça e minimizando o desgaste sofrido pelos litigantes com o trâmite do processo.

Além da tentativa de conciliação - objetivo principal de tal audiência - o parágrafo $2^{\circ}$ do artigo 331 traz as providências que o juiz deve tomar em caso de frustrada a composição amigável, devendo preparar o feito através do saneamento do processo, da fixação dos pontos controvertidos e da delimitação da atividade probatória das partes objetivando a uma instrução otimizada e que garanta, dessa forma, a agilidade necessária ao processo.

A questão da eficácia e celeridade da prestação jurisdicional não é tema recente e vem suscitando, há muito tempo, a atenção de juristas e doutos na busca de instrumentos que atendam ao manifesto descontentamento dos jurisdicionados, afastando suas desconfianças frente à Justiça. Garante-se assim o acesso ao Judiciário e reforça-se a confiança da sociedade brasileira numa solução célere e eficaz dos conflitos decorrentes das relações sociais.

Conforme assevera a Min. Fátima Nancy Andrighi, “o cidadão deve acreditar que uma vez levado seu problema jurídico às portas do Judiciário, esse será não só ouvido como, principalmente, solucionado em tempo hábil, pois são nefastas as conseqüências do descrédito dos cidadãos na Justiça, bem como as do seu desestímulo em buscá-la” ${ }^{1}$.

\footnotetext{
${ }^{1}$ ANDRIGHI, Fátima Nancy. O instituto da conciliação: a reforma processual. Publicação, 1994. Disponível em URL: <http://bdjur.stj.gov.br>. Acesso em 16/01/07
} 
Há que se ressaltar também, os outros métodos de solução não contenciosa dos litígios, como por exemplo, a mediação e a arbitragem, que promovem o mesmo resultado, qual seja, a satisfação da pretensão, porém, de maneira mais rápida e menos onerosa que a justiça comum, e muitas vezes com qualidade superior, já que as partes resolvem seus conflitos não como adversários mas como partícipes de um mesmo debate, buscando uma solução em comum.

A relevância do tema é irrefutável dada a atualidade da matéria e a necessidade imperiosa de se levar a efeito os instrumentos processuais existentes, $v$. g., a audiência preliminar do artigo 331 do CPC, bem como a utilização de soluções alternativas ao processo contencioso, de forma a evitar a morosidade da prestação jurisdicional e seu descrédito junto à sociedade.

Busca-se, dessa forma, demonstrar que a audiência preliminar prevista no artigo 331 do CPC é meio eficaz de celeridade processual, conforme muito bem anota Kazuo Watanabe que, "os poucos magistrados que alcançaram o real objetivo do legislador estão dando à lei aplicação correta e estão alcançando, com isto, índices expressivos de soluções amigáveis ou conduzindo mais adequadamente a instrução probatória” ${ }^{2}$.

\section{Conciliação no ordenamento jurídico brasileiro e a evolução do instituto no Código de Processo Civil.}

O instituto da conciliação está presente em nosso ordenamento jurídico desde a época do Império, onde a Constituição de 1824, em seu artigo 161, previa que não seria iniciado processo algum se não se constasse que havia sido intentado o meio da reconciliação. Também o “Código de Processo Criminal do Império de Primeira Instância com Disposição Provisória Acerca da Administração da Justiça Civil”, Lei datada de 1832, dispunha expressamente a possibilidade de se recorrer ao Juiz de paz para a solução do litígio.

No Regulamento 737 de 1850, bem como na Consolidação de Ribas, que passou a ter força de lei em 1876 (resultado da reunião das Ordenações Filipinas e de todas as suas alterações), realizado pelo Conselheiro Antonio Joaquim Ribas que, além de compilar as Ordenações e suas modificações também as reescreveu, também foi previsto a exigência da tentativa de composição antes da propositura da causa.

\footnotetext{
${ }^{2}$ WATANABE, Kazuo. Cultura da sentença e cultura da pacificação in Estudos em homenagem à Professora Ada Pelegrini Grinover, São Paulo, DPJ Ed., 2005.
} 
Mesmo após a República, pelo Decreto $\mathrm{n}^{\circ}$ 359, de 1890, que extingui a obrigatoriedade da tentativa conciliatória, alguns Estados da Federação a mantiveram em caráter facultativo. No entanto, o Código de Processo Civil de 1939, que reinstaurava legislação única, federal, para todo o país, não incorporou o instituto da conciliação em nenhum de seus dispositivos, que ressurgiu com a entrada em vigor da Consolidação das Leis do Trabalho em 1943, que previa a conciliação em dois momentos da audiência de instrução, ao inicio e ao final. Contudo, somente com o Código de Processo Civil de 1973 (ainda em vigor, porém com diversas alterações), o dever de conciliar foi inserido em caráter de generalidade, “como iniciativa oficial e incidental do juiz nas causas em que discutidos direitos patrimoniais passiveis de transação" ${ }^{3}$. Desta vez, a tentativa de conciliação ocorreria na audiência de instrução e julgamento.

Embora houvesse "relativo" 4 sucesso com a reintrodução do instituto, foi editada a Lei $\mathrm{n}^{\circ}$ 8.952, de 13 de dezembro de 1994, visando corrigir algumas falhas, acrescentando entre outras modificações, o inciso IV no artigo 125, instituindo como dever do juiz, tentar, a qualquer tempo, conciliar as partes, bem como, dando nova redação ao artigo 331 e parágrafos, onde foi proposto um momento especial para a tentativa de conciliação, destacando uma audiência específica antes da audiência de instrução e julgamento para a tentativa de composição amigável entre as partes e, em caso de ser frustrada tal tentativa, passa-se à etapa de saneamento do processo, delimitando a atividade probatória das partes, fixando os pontos controvertidos e decidindo as questões processuais pendentes. Buscou-se, dessa forma, minimizar a crise judiciária, dando maior celeridade aos atos processuais possibilitando aos litigantes a satisfação efetiva de seu interesse.

Em 1988, a Constituição da República Federativa do Brasil, fundada na harmonia social e comprometida, na ordem interna e internacional, com a solução pacífica das controvérsias, previu em seu artigo 98, inciso I, a criação de juizados especiais competentes para a conciliação, o julgamento e a execução de causas cíveis de menor complexidade e infrações penais de menor potencial ofensivo, mediante os procedimentos oral e sumaríssimo. O parágrafo $1^{\circ}$ dispõe sobre a criação de juizados especiais também no âmbito da Justiça Federal. A regulamentação de tal dispositivo se deu em 1995, com a edição da Lei 9.099, que

\footnotetext{
3 DALL'AGNOL JUNIOR, Antonio Janyr. Sobre a audiência de conciliação. Curitiba: GenesisPro, n. 2, maio/ago. 1996, pag 300.

4 Antonio Janyr Dall’Agnol Junior, lembra que embora não existissem estatísticas seguras, houve relativo sucesso com a reintrodução do instituto; e o "relativo" corre mais por conta do momento em que situada a tentativa e, por vezes, do modo como a vêem os operadores do processo (não só os juizes, como também os advogados a convencerem seus clientes do sucesso final, o que sabidamente, as mais das vezes é uma temeridade). GenesisProc 2/300, 1996
} 
criou os Juizados Especiais Cíveis e Criminais no âmbito estadual, e com a Lei 10.259/2001, no âmbito federal.

Em 2002, com a Lei 10.444, a audiência preliminar passa a ser facultativa, permitindo ao juiz sanear desde logo o processo nos casos em que o direito em litígio não admitir transação ou se as circunstâncias da causa evidenciarem ser improvável sua obtenção.

A emenda constitucional $\mathrm{n}^{\circ}$ 45, de 8 de dezembro de 2004, alterou o inciso LXXVIII do artigo $5^{\circ}$, elevando a direito e garantia fundamental a razoável duração do processo, bem como os meios que garantam a celeridade de sua tramitação. Neste ponto, a conciliação, seja ela obtida judicial ou extrajudicialmente, possui papel de fundamental importância como instrumento de economia e celeridade processual.

\section{A Audiência Preliminar do artigo 331.}

A Lei $n^{\circ}$ 8.952, de 13 de dezembro de 1994, alterou a redação do artigo 331 e seus parágrafos, instituindo a audiência de conciliação, como ato e momento próprio, antes da audiência de instrução e julgamento, seguindo tendência modernizadora do processo civil, como se verifica:

\footnotetext{
Art. 331. Se não se verificar qualquer das hipóteses previstas nas seções precedentes e a causa versar sobre direitos disponíveis, o juiz designará audiência de conciliação, a realizar-se no prazo máximo de trinta dias, à qual deverão comparecer as partes ou seus procuradores, habilitados a transigir.

$\S 1^{\circ}$. Obtida a conciliação, será reduzida a termo e homologada por sentença.

$\S 2^{\circ}$. Se, por qualquer motivo, não for obtida a conciliação, o juiz fixará os pontos controvertidos, decidirá as questões processuais pendentes e determinará as provas a serem produzidas, designando audiência de instrução e julgamento, se necessário.
}

É premente a intenção em se dar maior atenção à composição amigável entre as partes, ao destacar uma audiência própria para a tentativa de conciliação, objetivo precípuo de tal audiência, precipitando assim, a extinção do processo, antes que seja despendido todo tempo e recursos financeiros para a produção de provas visando à audiência de instrução e julgamento, e que, muitas vezes, se mostravam até mesmo desnecessárias, bem como dando resposta célere e eficaz ao anseio das partes. A audiência preliminar prevista no art. 331 do CPC propõe a valorização da conciliação entre as partes, como expressão máxima do principio da oralidade, proporcionando maior agilidade à realização da Justiça e minimizando o desgaste sofrido pelos litigantes com o trâmite do processo.

Fica patente a preocupação do legislador reformista, conforme assevera o ilustre processualista Humberto Theodoro Junior “em dar resposta à generalizada insatisfação ou 
desconfiança frente à Justiça” 5 , e o intuito de garantir uma efetiva prestação jurisdicional, sendo que "a audiência de conciliação resulta na consagração do juiz como pacificador social, relegando a segundo plano sua função de mero aplicador da lei” 6 .

Nelson Nery Junior ${ }^{7}$ lembra que,

O comparecimento pessoal da parte à audiência preliminar é um ônus e não obrigação. No caso da parte não comparecer, regularmente intimada, há apenas a impossibilidade de efetivar-se a tentativa de conciliação, já que não há previsão da aplicação de penalidade processual, como existe por exemplo, no direito alemão (pena de revelia - §141, III, da ZPO) e no Código de Processo Civil-Tipo para a América Latina (autor: desistência da ação, art. 300.2; réu: presunção de veracidade dos fatos afirmados pelo autor, art. 300.3).

Tentativa de conciliação. Conforme já observado anteriormente, este é o primeiro e principal ato processual a ser praticado na audiência preliminar. Embora tenha sido previsto momento próprio para a tentativa de composição entre os litigantes, a regra dos artigos 447 e 448, no que diz respeito à tentativa de conciliação antes de se dar inicio à audiência de instrução e julgamento, não foi derrogada pelo artigo 331, pois cabe ao juiz buscar o acordo amigável em qualquer fase do processo.

A conciliação poderá ser obtida total ou parcialmente, sendo homologada pelo juiz, através de sentença ( $\left(1^{\circ}\right.$, art. 331), assumindo a natureza de título executivo judicial (art. 475N, III). No caso de se obter a transação apenas sobre parte do litígio, o juiz homologará o tocante ao acordo e dará seguimento ao procedimento no que disser respeito à parte não acordada. A conciliação poderá ser também ampliada, abrangendo matéria não posta em juízo anteriormente, como se pode aferir da leitura do inciso III do artigo 475-N, ao considerar como título executivo judicial a sentença de homologação da conciliação ou transação, mesmo se incluírem matéria não posta em juízo.

Fixação dos pontos controvertidos e delimitação dos meio de prova. Nesse momento, somente a matéria controversa é importante, situação em que, os pontos afirmados pelo autor na inicial são controvertidos pelo réu na contestação. É providencia de total importância, pois é aqui que o juiz evidenciará e determinará quais meios de prova deverão ser utilizadas e em que extensão, devendo-o fazer o mais objetivamente possível.

Discutir-se-á sobre a necessidade de realização de prova pericial, oral e mesmo a inspeção judicial. O enfoque será dado não só quanto à pertinência e a relevância, que tem em

\footnotetext{
${ }^{5}$ THEODORO JUNIOR, Humberto. Celeridade e efetividade da prestação jurisdicional. Revista TrinoLex. com, ano 1, n. 2, jan/fev 2005, pag 31

${ }^{6}$ ANDRIGHI, Fátima Nancy. O instituto da conciliação: a reforma processual. Publicação, 1994. Disponível em URL: <http://bdjur.stj.gov.br>. Acesso em 16/01/07

${ }^{7}$ NERY JUNIOR, Nelson. Audiência preliminar e saneamento do processo, in Reforma do Código de Processo Civil, coord. Sálvio de Figueiredo Teixeira, Saraiva: São Paulo, 1996. pag 340.
} 
vista a matéria alegada, mas também sobre a adequação, conforme bem observa Antonio Janyr Dall’Agnol Junior (1996).

Sobre esse assunto, Wambier ${ }^{8}$ afirma que,

O juiz exerce atividade tendente a levar a efeito o principio da economia processual, pois que limita o campo dentro do qual devem ocorrer as discussões, traça os contornos do objeto da prova, determinando o tipo de prova que deve ser produzida (...) e evita que as atividades das partes fujam do eixo do processo, fixado, nessa ocasião, pelo juiz.

Saneamento do processo. Nessa fase da audiência preliminar, o juiz irá sanear as questões que ainda se encontrem pendentes, pois

\begin{abstract}
a atividade saneadora do juiz, a quem compete o controle da regularidade do procedimento, inicia-se quando da propositura da demanda, com o exame, que deve realizar, da inicial, determinando emendas ou mesmo rejeitando-as, quando inviável outra solução ${ }^{9}$.
\end{abstract}

Se, mesmo após tais providências, ainda persistirem vícios, ou sobrevierem alguns, o juiz deverá tomar as providências previstas no $\S 2^{\circ}$ do artigo 331, realizando o saneamento do feito e regularizando o processo.

Muito se discutiu, quando da reforma do artigo 331 pela Lei $\mathrm{n}^{0} 8.952 / 94$, se a audiência de conciliação então prevista era ou não obrigatória. Em opinião quase unânime dos doutrinadores, concluiu-se, como se pode observar, que

\begin{abstract}
caso o juiz não designe essa audiência, ou profira a decisão de saneamento sem o fazer preceder da audiência preliminar, há nulidade do processo. Se a lei prevê o ato é porque vê nessa audiência um ato útil, que pode fornecer elementos para o juiz tentar conciliar as partes efetivamente, sanear o feito e fixar os pontos controvertidos com segurança ${ }^{10}$.
\end{abstract}

\title{
3.1. Reforma da Lei $10.444 / 02$.
}

Quando da inserção do instituto da audiência preliminar pela Lei 8.952/94, muito se debateu sobre o assunto, principalmente quanto à questão de sua obrigatoriedade; sobre sua própria denominação, onde o texto da lei se referia à designação de "audiência de conciliação”; bem como sobre a expressão contida no caput do artigo 331, referente a causas que versassem sobre direitos disponíveis.

\footnotetext{
${ }^{8}$ WAMBIER, Luiz Rodrigues. A nova audiência preliminar (art. 331 do CPC) RePro 80/30.

9 DALL'AGNOL JUNIOR, Antonio Janyr. Sobre a audiência de conciliação. Curitiba: GenesisPro, n. 2, maio/ago. 1996, pag 300.

${ }^{10}$ NERY JUNIOR, Nelson. Audiência preliminar e saneamento do processo, in Reforma do Código de Processo Civil, coord. Sálvio de Figueiredo Teixeira, Saraiva: São Paulo, 1996. Ainda nesse sentido: Candido Rangel Dinamarco (A reforma do código de processo civil, $5^{a}$ ed, Malheiros: São Paulo, 2001); Humberto Theodoro Junior (Curso de direito processual civil, vol I, Ed Forense: Rio de Janeiro, 2005); José Rogério Cruz e Tucci (Horizontes da nova audiência preliminar, Revista Forense, Vol 370, 2003); Luiz Fernando Tomaso Keppen (Aspectos da reforma do código de processo civil, RePro 84/42); Rogério Lauria Tucci (A nova fase saneadora do processo brasileiro, in Reforma do código de processo civil, coord. Sálvio de Figueiredo Teixiera. Ed Saraiva: São Paulo, 1996); entre outros
} 
Já desde sua implantação no ordenamento jurídico, muitos doutrinadores preferiram denominá-la “audiência preliminar”, visto que, a nova audiência proposta pelo artigo 331 não se referia tão somente à tentativa de conciliação, embora fosse seu objetivo primeiro, mas dispunha de uma série de procedimentos que o juiz deveria adotar caso não lograsse êxito na tentativa conciliatória.

A questão da disponibilidade do direito em litígio para a realização da audiência preliminar buscando-se a conciliação entre as partes foi muito debatida, pois há direitos que mesmo tidos como indisponíveis permitem a realização de acordo quando a pretensão gire em torno de sua mensuração econômica - clássico exemplo é o referente às ações de natureza alimentar, onde é perfeitamente possível que se acorde sobre o quantum a ser pago. Mesmo que não seja possível a obtenção da conciliação, o juiz definirá os contornos da matéria a ser discutida no processo, inclusive com a fixação dos pontos sobre que incidirá a prova, sendo esta atividade imprescindível, mesmo nas causas a respeito de direito indisponível ${ }^{11}$.

No tocante à obrigatoriedade da audiência preliminar, em pensamento praticamente unânime, a doutrina considerou ser obrigatória a instauração de tal audiência sob pena de nulidade processual. No entanto há quem discorde desse posicionamento ${ }^{12}$, pois que a obrigatoriedade de mais uma audiência, mesmo quando os direitos em litígio não permitirem a transação ou naqueles casos em que improvável ou impossível a obtenção da autocomposição, não contribui para a celeridade do procedimento, concorrendo para o aumento no volume do trabalho forense.

Já em 1995, no Congresso Brasileiro de Direito Processual Civil, realizado em Brasília de 19 a 22 de junho, houve a reunião de diversos doutrinadores - em Mesa-Redonda - onde foi discutida a perspectiva de alterações da legislação processual civil, havendo a sugestão de incluir-se ao artigo 331 um parágrafo $3^{\circ}$, regulando a questão dos direitos indisponíveis, para que o saneamento do processo fosse feito fora da audiência prevista no citado artigo ${ }^{13}$.

De fato, em 2002, com a reforma produzida pela Lei 10.444, de 7 de maio, houve alteração do caput do artigo 331 referente a direitos que admitam transação, bem como ocorreu alteração da denominação de tal audiência, passando de audiência de conciliação para

\footnotetext{
${ }^{11}$ Sobre esse assunto: WAMBIER, Luiz Rodrigues. A nova audiência preliminar (art. 331 do CPC) RePro 80/34 e 35; NERY JUNIOR, Nelson. Audiência preliminar e saneamento do processo, in Reforma do Código de processo civil, coord. Sálvio de Figueiredo Teixeira, São Paulo: Saraiva, 1996, pag 339; TUCCI, Rogério Lauria. A nova fase saneadora do processo civil brasileiro, in Reforma do Código de processo civil, coord. Sálvio de Figueiredo Teixeira, São Paulo: Saraiva, 1996, pag 356, 357.

12 GAJARDONI. Fernando da Fonseca. Técnicas de aceleração do processo. São Paulo: Lemos e Cruz, pag 149, 150

${ }^{13}$ NERY JUNIOR, Nelson. Audiência preliminar e saneamento do processo, in Reforma do Código de processo civil, coord. Sálvio de Figueiredo Teixeira, São Paulo: Saraiva, 1996, pag 344.
} 
audiência preliminar, e a inserção de um parágrafo $3^{\circ}$, que a tornou facultativa, sendo disciplinada da seguinte forma:

\begin{abstract}
Art. 331. Se não ocorrer qualquer das hipóteses previstas nas seções precedentes e a causa versar sobre direitos que admitam transação, o juiz designará audiência preliminar, a realizar-se no prazo máximo de trinta dias, para a qual serão as partes intimadas a comparecer, podendo fazer-se representar por procurador ou preposto, com poderes para transigir.

$\S 1^{\circ}$. Obtida a conciliação, será reduzida a termo e homologada por sentença.

$\S 2^{\circ}$. Se, por qualquer motivo, não for obtida a conciliação, o juiz fixará os pontos controvertidos, decidirá as questões processuais pendentes e determinará as provas a serem produzidas, designando audiência de instrução e julgamento, se necessário.

$\S 3^{\circ}$. Se o direito em litígio não admitir transação, ou se as circunstâncias da causa evidenciarem ser improvável sua obtenção, o juiz poderá, desde logo, sanear o processo e ordenar a produção da prova, nos termos do $2^{\circ}$.
\end{abstract}

As modificações introduzidas pela Lei 10.444/02, vieram ao encontro dos diversos estudos doutrinários realizados quando da reforma da Lei 8.952/94, que introduziu uma audiência preliminar em nosso Código de Processo Civil.

No entanto, a inserção do parágrafo $3^{\circ}$ ao artigo 331, que tornou a aludida audiência facultativa, permitindo ao juiz proceder ao saneamento do processo por escrito, como ocorria anteriormente, antes da reforma de 1994 e de conformidade com o disposto no parágrafo $2^{\circ}$ do artigo 331, gerou, mais uma vez, diversos debates por parte da doutrina que se divide ao analisar a discricionariedade do juiz em designar a audiência preliminar quando evidente a improbabilidade de conciliação entre as partes.

Muitos consideram a novidade um avanço, pois que impede a realização de audiências tidas como inúteis, contribuindo para o desafogamento das pautas quase sempre assoberbadas dos juízes, evitando perda de tempo e de atividade processual com a prática de ato complexo, cujo objetivo principal - a conciliação - se mostrasse frustrada. Apesar disso, acreditam que essa facultatividade deve ser recebida com cautela, a fim de que não se banalize o instituto, e que os juizes não usem essa faculdade de modo indiscriminado, pois uma adequada aplicação do artigo 331, pode contribuir sobremaneira para a obtenção de uma tutela jurisdicional mais célere e eficiente ${ }^{14}$.

\footnotetext{
${ }^{14}$ São favoráveis à facultatividade: CARNEIRO, Athos Gusmão. Audiência de instrução e julgamento $e$ audiências preliminares, $13^{\mathrm{a}}$ ed., Rio de Janeiro: Forense, 2007; GAJARDONI. Fernando da Fonseca. Técnicas de aceleração do processo. São Paulo: Lemos e Cruz; MOREIRA, José Carlos Barbosa. Vicissitudes da audiência preliminar. Revista Forense, vol 374, 2004 (este autor considera ser primordial a justificação da opção de não designar a audiência, pelo juiz, indicando os sinais que o convenceram de ser ela improvável. Considera ainda que o silêncio a esse respeito abre a possibilidade de embargos de declaração, e a motivação exposta é passível de controle pelo órgão de segundo grau, mediante agravo); SIQUEIRA, Cleanto Guimarães. As novíssimas alterações do código de processo civil, Rio de Janeiro: Forense, $1^{\mathrm{a}}$ ed., 2003; WAMBIER, Luiz Rodrigues. ALVIM WAMBIER, Teresa Arruda. Breves comentários à $2^{a}$ fase da reforma do código de processo civil, $2^{\circ}$ ed., São Paulo: Revista dos Tribunais, 2002.
} 
Aqueles que assumem posição contrária, consideram a inovação inserida pelo parágrafo $3^{\circ}$, um retrocesso, pois que a audiência preliminar instituída se configura como o princípio máximo da oralidade, sendo que a importância de tal audiência não está somente no fato de se precipitar à extinção do processo através da transação entre as partes, mas também resultam de extrema importância as providências que o legislador adotou no parágrafo $2^{\circ}$, sobretudo pela definição do objeto do processo em trabalho de franca e direta cooperação entre juiz e partes, valorizando-se esse estágio procedimental, por meio do qual se concentra o tema do debate e se definem as provas pertinentes e admissíveis. Asseguram ainda, que a incidência da audiência em questão torna-se utópica, já que a faculdade prevista possibilita que os juizes se esquivem da realização da audiência preliminar, valendo-se da abertura deixada pelo legislador reformista ${ }^{15}$.

\section{Audiência Preliminar como instrumento efetivo de celeridade e efetividade da prestação jurisdicional.}

Sintetizando o pensamento do Professor Moacyr Amaral Santos, as condições de uma boa lei processual, corresponde a certos regramentos que devem informa-la: simplicidade das formas processuais; economia na efetivação do processo ; e, celeridade na prestação jurisdicional ${ }^{16}$. É exatamente esse o espírito da Lei ${ }^{\circ}$ 8.952/94, quando institui momento próprio para uma audiência preliminar, tendo como objetivo principal, a conciliação entre as partes, encerrando o processo e permitindo uma rápida prestação jurisdicional e a satisfação dos litigantes. A previsão de saneamento do processo contida no $\S 2^{\circ}$,

consubstancia medida de flagrante economia de tempo, especialmente porque ao julgador cabia como cabe zelar para que a produção da prova se restrinja ao fato ou fatos probandos. Na verdade, da forma como idealizada e se bem implementada, a audiência preliminar presta-se a fomentar a inafastável interação entre os primordiais protagonistas do processo ${ }^{17}$.

Podemos encontrar vários exemplos na doutrina de diversos países que instituíram em seu ordenamento uma audiência preliminar ou audiência prévia, ou algum procedimento que vise a celeridade e simplicidade, dando a idéia de um juiz mais ativo no processo, buscando a satisfatividade das partes, com elevados índices de acordos e garantindo uma solução célere e

\footnotetext{
${ }^{15}$ Nesse sentido: DINAMARCO, Candido Rangel. A reforma da reforma, $4^{\mathrm{a}}$ ed., São Paulo: Malheiros, 2002; CRUZ E TUCCI, José Rogério. Horizontes da nova audiência preliminar, Revista Forense, vol 370, 2003; THEODORO JUNIOR. Humberto. Curso de direito processual civil, vol I, 42a ed., Rio de Janeiro: Forense, 2005.

${ }^{16}$ Moacyr Amaral Santos, As condições da ação no despacho saneador, tese, São Paulo, 1946, p. 7-10 APUD Rogério Lauria Tucci, A nova fase saneadora do processo civil, cit., p. 348.

17 TUCCI, José Rogério Cruz e. Horizontes da nova audiência preliminar, Revista Forense, Vol 370, 2003
} 
eficaz aos anseios da sociedade. Pode-se citar o "Modelo de Stuttgart de audiência no processo civil”, que alcançou grande êxito na República Federal da Alemanha; bem como no direito austríaco (die erste Tagzatzung); no direito inglês (Summons of directions); no direito norte-americano (pré-trial); no direito português com o instituto do despacho saneador ; no direito espanhol; e, o Código de Processo Civil Tipo para a América Latina, que se caracteriza como um trabalho de doutrina pretendendo ser um modelo aos legisladores dos diversos paises filiados, como sugestão para possíveis reformas ${ }^{18}$.

Conforme bem anota o Professor Kazuo Watanabe,

idêntica idéia, de um juiz mais ativo na condução dos processos, é o fundamento principal do artigo 331 do nosso estatuto processual (...) Os poucos magistrados que alcançaram o real objetivo do legislador estão dando à lei aplicação correta e estão alcançando, com isto, índices expressivos de soluções amigáveis ou conduzindo mais adequadamente a instrução probatória ${ }^{19}$.

Observa também que, hoje, há uma valorização da chamada cultura da sentença. Por várias razões, a percepção que os juízes tem de que seu merecimento será aferido principalmente, pelas boas sentenças por ele proferidas, bem como, a formação acadêmica dos operadores de Direito que é voltada fundamentalmente para a solução contenciosa dos conflitos, entre outras, “os juízes preferem proferir sentença ao invés de tentar conciliar as partes para a obtenção da solução amigável dos conflitos. Sentenciar é mais fácil e mais cômodo, para alguns juízes, do que pacificar os litigantes...” 20.

Ainda sobre o assunto, Walter Ceneviva explicita que, embora sejam apontados alguns defeitos pela doutrina, estes não são mais relevantes que a qualidade da tentativa de conciliação que, além de dar velocidade à solução dos conflitos, contribui para a preservação da paz social "até porque põe de lado as questões de fato e as de direito substancial ou processual alegadas, para chegar à conciliação, enquanto exercício jurisdicional, em seu melhor entendimento moderno" ${ }^{21}$.

A Ministra do Superior Tribunal de Justiça, Fátima Nancy Andrighi, em diversas palestras proferidas para discussão do assunto ora estudado, ressalta a importância das audiências de conciliação, como meio de celeridade processual, dando resposta aos anseios

\footnotetext{
${ }^{18}$ Para maior análise do tema consultar os trabalhos de Candido Rangel Dinamarco, A reforma do código de processo civil, Ed. Malheiros: São Paulo, 2001; José Carlos Barbosa Moreira, Saneamento do processo e audiência preliminar, RePro 40/109; Rogério Lauria Tucci, A nova fase saneadora do processo brasileiro, in Reforma do código de processo civil, coord. Sálvio de Figueiredo Teixiera. Ed Saraiva: São Paulo, 1996.

${ }^{19}$ WATANABE, Kazuo. Cultura da sentença e cultura da pacificação in Estudos em homenagem à Professora Ada Pelegrini Grinover, São Paulo, DPJ Ed., 2005.

${ }^{20}$ WATANABE, Kazuo. Cultura da sentença e cultura da pacificação in Estudos em homenagem à Professora Ada Pelegrini Grinover, São Paulo, DPJ Ed., 2005.

${ }^{21}$ CENEVIVA, Walter. Conciliação no processo civil brasileiro in Reforma do código de processo civil, coord. Sálvio de Figueiredo Teixiera. Ed Saraiva: São Paulo, 1996.
} 
sociais, "que há muito vem reclamando uma justiça célere e eficaz, hábil a solucionar com presteza necessária os conflitos que decorrem das relações sociais” ${ }^{22}$. Salienta ainda, que, pode-se observar que a audiência de conciliação não tem alcançado índices tão satisfatórios, como previa o legislador reformista, sendo necessário uma mudança de mentalidade, tanto do povo brasileiro, quanto, principalmente, de todos os artífices do direito para as benesses da resolução rápida dos conflitos, seja através da conciliação judicial, seja através dos meio alternativos de solução dos litígios.

Ressalta a experiência conciliatória, que cada vez mais tem encontrado espaço nos ordenamentos jurídicos de todos os países, face à sua comprovada eficiência. Como exemplo, demonstra o número de acordos alcançados pelos Estados Unidos com as audiências pré-trial, com um percentual equivalente a 90\% na Justiça Federal e 75\% na Justiça Estadual.

E para finalizar, afirma ainda que, "no decorrer do exercício da atividade jurisdicional, depois de algum tempo, se aprende que o processo adversarial sempre separa, enquanto que a busca da solução consensual do litígio aproxima e preserva as relações; que a opção pela conciliação é que nos conduz à tão sonhada e necessária humanização da justiça”, 23.

\section{Outras formas de solução dos conflitos}

Em virtude da crescente insatisfação da população frente à morosidade do Poder Judiciário que não tem conseguido dar respostas rápidas e eficazes aos problemas que lhe são propostos, tem-se insistentemente, buscado formas alternativas de solução dos conflitos, formas estas que valorizem a composição extrajudicial, sem que seja preciso toda a movimentação da máquina do judiciário ao se buscar uma sentença que atenda a pretensão das partes, ou de pelo menos uma delas - no caso a parte vencedora. Muitas vezes, a sentença que põe fim ao processo não põe fim ao conflito, pois que permanece aquele sentimento de discórdia e rivalidade entre os litigantes, sendo possível que surjam novas demandas em virtude de uma situação mal resolvida anteriormente.

A questão da busca de soluções alternativas à resolução dos conflitos sem que se passe pelo crivo do Poder Judiciário, é problema internacional e não exclusividade brasileira. Podese citar como exemplo as Alternative Dispute Resolutions - $A D R$, dos norte-americanos; os

\footnotetext{
${ }^{22}$ ANDRIGHI, Fátima Nancy. O instituto da conciliação: a reforma processual. Publicação, 1994. Disponível em URL: <http://bdjur.stj.gov.br>. Acesso em 16/01/07

${ }^{23}$ ANDRIGHI, Fátima Nancy. Conciliação e realidade brasileira. Palestra proferida na V Jornada Brasileira de Direito Processual Civil, Foz do Iguaçu, 08/08/2003. Disponível em URL: <http://bdjur.stj.gov.br>. Acesso em 16/01/07.
} 
Médios alternativos de reslución de conflictos, dos espanhóis; os Métodos alternativos de solución o manejo de conflictos - MASC, dos equatorianos ${ }^{24}$.

No Brasil, podemos citar como um dos métodos alternativos de solução dos conflitos, a arbitragem, instituída pela Lei $\mathrm{n}^{\circ}$ 9.307, de 23 de setembro de 1996, que tem por objetivo dirimir litígios relativos a direitos patrimoniais disponíveis. As partes interessadas podem submeter a solução de seus litígios ao juízo arbitral mediante convenção de arbitragem, que pode ser feita através de cláusula compromissória (convenção através da qual as partes em um contrato comprometem-se a submeter à arbitragem os litígios que possam vir a surgir, relativamente a tal contrato, devendo ser estipulada por escrito, no próprio contrato ou em documento apartado que a ele se refira), ou através do compromisso arbitral (convenção através da qual as partes submetem um litígio à arbitragem de uma ou mais pessoas, podendo ser judicial ou extrajudicial).

Lílian Matsuura ${ }^{25}$, considera que

a arbitragem privada é alternativa vantajosa para disputas de alta complexidade que, em geral, não encontram na justiça estatal o grau de conhecimento técnico necessário para a adequada solução do conflito. O custo da mediação é maior, mas compensa pela sua agilidade e pela qualidade do resultado.

Para Gabriela Nacarato ${ }^{26}$, em artigo publicado no site da Escola Paulista da Magistratura:

\begin{abstract}
Dentre as vantagens da arbitragem podemos citar a prevalência da vontade das partes; a rapidez do procedimento; a especialização dos árbitros, que, em razão da livre escolha das partes, sempre acabam por ser especialistas na matéria em litígio; a possibilidade de sigilo; o procedimento democrático e a possibilidade de decisão por equidade.

Por outro lado, a Arbitragem também apresenta desvantagens, tais como a existência de uma única decisão, que não mais poderá ser discutida quanto ao mérito (...). Entretanto, ainda que existam algumas desvantagens, a utilização da Arbitragem para a solução de conflitos fora do âmbito judicial é de grande valia (...). Pode-se concluir que o Instituto da Arbitragem foi criado com o intuito de conciliar a autonomia da vontade das partes (que prevalece em matéria de direitos disponíveis) com um julgamento definitivo, simples, célere e mais adequado às necessidades comerciais do mundo globalizado.
\end{abstract}

Uma outra forma alternativa de solução dos conflitos é a mediação que, de acordo com a Ministra Fátima Nancy Andrighi ${ }^{27}$,

\footnotetext{
${ }^{24}$ FREITAS, Vladimir Passos de. Judiciário busca alternativas para combater morosidade. Revista Consultor Jurídico, 22 de agosto de 2007. Disponível em: <http://conjur.estadao.com.br/static/text/58759,1. Acesso em: $15 / 09 / 2007$.

${ }^{25}$ MATSUURA, Lílian. Depois de 10 anos, lei de arbitragem começa a ter efeito. Revista Consultor Jurídico, 7 de julho de 2007. Disponível em: <http://conjur.estadao.com.br/static/text/57342,1>. Acesso em 15/08/2007.

${ }^{26}$ NACARATO, Gabriela. Arbitragem como um dos métodos alternativos para solução de conflitos. Disponível em: <http://www.epm.sp.gov.br/SiteEPM/Artigos/146.htm>. Acesso em 10/10/2007.
} 
alguns asseveram tratar-se da Justiça do Terceiro Milênio (...), técnica de resolução de conflitos não adversarial largamente utilizada em países do Oriente e Ocidente, cuja eficiência reside na diluição do conflito. O mediador auxilia as partes na busca da solução do litígio, sem imposição de sentença ou de laudos, preservando-lhes os interesses por meio de acordos criativos de benefícios recíprocos.

Entre as vantagens deste instituto, pode-se citar a rapidez com que são obtidos os resultados; redução nos custos, pois se evita o processo com todas suas despesas; privacidade e sigilo, pois cabe ao mediador manter sigilo dos fatos conhecidos nas reuniões de mediação; facilitação da comunicação entre as partes, que debatem entre si em busca da melhor solução para seu conflito; restabelecimento das relações sociais, evitando-se novos confrontos ${ }^{28}$.

A mediação transcende à solução de conflitos, dispondo a transformar o contexto adversarial em colaborativo, estimulando e vitalizando a comunicação entre os indivíduos em conflito de modo a proporcionar o que a jurisdição pública certamente não possui condições de oferecer, celeridade e restabelecimento da relação social entre as partes ${ }^{29}$.

\section{Resultados e discussão}

Conforme já observado anteriormente, o instituto da conciliação não é novidade no ordenamento jurídico brasileiro. A doutrina se debruçou com afinco a fim de analisar as vantagens e desvantagens da instituição de uma audiência preliminar que, além de valorizar a conciliação entre os litigantes, prevê também as providências que o juiz deve tomar em caso de ser frustrada tal tentativa, devendo preparar o feito para uma instrução otimizada e, conseqüentemente, promovendo o encerramento do processo em menor tempo.

Pode-se sintetizar o pensamento de grande parte da doutrina a respeito de tal instituto, utilizando-se as palavras de Celso Agrícola Barbi, para quem

são numerosas as vantagens da conciliação. Ela permite a satisfação mais veloz do direito das partes, evita a exaltação dos ânimos entre elas; é um fator de economia, visto que ameniza, para as partes, as despesas do curso normal de um processo;

27 ANDRIGHI, Fátima Nancy. Formas alternativas de solução de conflitos. Disponível em: $<$ http://bdjur.stj.gov.br>. Acesso em: 15/09/2007.

${ }^{28}$ Sobre o assunto, vide ainda: GRUNWALD, Astried Brettas. A mediação como forma efetiva de pacificação social no Estado Democrático de Direito . Jus Navigandi, Teresina, ano 8, n. 289, 22 abr. 2004. Disponível em: $<$ http://jus2.uol.com.br/doutrina/texto.asp?id=5117>. Acesso em: 15/09/2007; SILVA, João Carlos Almeida. Mediação. Disponível em: http://www.webartigos.com/articles/2171/1/MEDIAÇÃO/Pagina1.html. Acesso em: 15/09/2007; SOUSA, Lilia Almeida. A utilização da mediação de conflitos no processo judicial. Jus Navegandi, Teresina, ano 9, n. 568, 26 jan. 2005. Disponível em: <http://jus2.uol.com.br/doutrina/texto.asp?id=6199>. Acesso em: 15/09/2007

${ }^{29}$ GRUNWALD, Astried Brettas. A mediação como forma efetiva de pacificação social no Estado Democrático de Direito . Jus Navigandi, Teresina, ano 8, n. 289, 22 abr. 2004. Disponível em: $<$ http://jus2.uol.com.br/doutrina/texto.asp?id=5117>. Acesso em:15/09/2007. 
permite o melhor funcionamento do Poder Judiciário em outros feitos, pois diminui o trabalho dos juizes e dos funcionários nas causas em que tem lugar ${ }^{30}$.

Apesar do consenso que pode ser observado em vários estudos doutrinários, palestras e seminários realizados acerca da utilidade da audiência preliminar e das vantagens da conciliação para aceleração do processo, nota-se, através do relato da experiência de estudiosos, bem como através do resultado de algumas pesquisas de campo já existentes, que a audiência preliminar não tem se mostrado tão frutífera.

Em pesquisa de campo realizada em 2002 pelo Professor Doutor da Faculdade de Direito de Franca e Juiz de Direito no Estado de São Paulo, Fernando da Fonseca Gajardoni, para aferição da eficácia das reformas legislativas visto a inexistência de dados sobre o assunto, ficou demonstrado, em relação à porcentagem de acordos obtidos em audiência do artigo 331 do CPC, um índice razoavelmente baixo na Justiça Estadual Paulista, onde aproximadamente 28,9\% das audiências do artigo 331 frutificaram em práticas autocompositivas $^{31}$.

Em outra pesquisa, realizada por Artur Stamford, Professor Adjunto da Universidade Federal de Pernambuco, acerca da conciliação judicial, mostra que das 47 audiências assistidas para realização do trabalho, apenas 12 tiveram acordo assinado, ou seja, apenas $25,5 \%{ }^{32}$.

Em relatório intitulado “Avaliação dos Juizados Especiais Cíveis”, que expõe os resultados da pesquisa nacional realizada pelo Centro Brasileiro de Estudos e Pesquisas Judiciais - CEBEPEJ - no período de dezembro de 2004 a fevereiro de 2006, verificou-se um percentual de acordo de 34,5\%, índice extremamente abaixo do esperado, considerando que a pacificação dos conflitos por meio de solução amigável é a principal filosofia dos Juizados Especiais. Quando se analisa a obtenção de acordos quando os reclamantes estão acompanhados por advogado, esse índice cai para 20\%, sendo possível sustentar que a possibilidade de acordos diminui quando o reclamante vai à audiência com advogado.

Analisando a questão dos baixos índices de acordos, bem como a não obtenção dos resultados esperados, vários doutrinadores consideram como causa o não envolvimento dos protagonistas do ato conciliatório, ou seja, juízes e advogados. Neste aspecto, considera-se certa falta de disposição dos juizes e demais operadores do direito à tentativa de conciliação

\footnotetext{
${ }^{30}$ BARBI, Celso Agrícola. O papel da conciliação como meio de evitar o processo e de resolver conflitos. RePro 39/121.

${ }^{31}$ GAJARDONI. Fernando da Fonseca. Técnicas de aceleração do processo. São Paulo: Lemos e Cruz, pag 237.

${ }^{32}$ STAMFORD, Artur. Etnometodologia da conciliação judicial: uma análise do cotidiano forense. Disponível em URL: http://www.conpedi.org/manaus/arquivos/Anais/Artur\%20Stamford.pdf. Acesso em 14/05/2007.
} 
que, como expressão máxima do princípio da oralidade exige dos participantes tempo e disposição, e nas palavras da Ministra Fátima Nancy Andrighi, "humildade, para se alongarem nas explicações e, acima de tudo, paciência, para ouvir as partes em conflito” ${ }^{33}$. Conforme Andrighi ${ }^{34}$, “a reversão do quadro atual depende muito mais da transformação do comportamento dos integrantes dos vários segmentos profissionais que participam ativamente da operacionalização dos serviços judiciários, do que pura modernização das leis processuais”.

Neste ponto, observa-se que é primordial que a formação acadêmica, principalmente, deve ser voltada para a formação de conciliadores que busquem meios alternativos de resolução dos conflitos, pois

toda ênfase é dada à solução dos conflitos por meio do processo judicial, onde é proferida uma sentença, que constitui a solução imperativa dada pelo representante do Estado. O que se privilegia é a solução pelo critério do 'certo ou errado', do 'preto ou branco', sem qualquer espaço para a adequação da solução, pelo concurso da vontade das partes, à especificidade de cada caso ${ }^{35}$.

O consultor Ari Lima, conclui ainda que, a capacidade de negociação deveria ser uma prioridade na formação de todos os operadores do direito. Uma competência a ser disseminada nas escolas, nos escritórios de advocacia e nas instituições judiciárias, para que as demandas judiciais possam conseguir soluções menos traumáticas e mais adequadas às partes envolvidas e para a sociedade em geral ${ }^{36}$.

Em pesquisa de campo efetuada, entre os meses de agosto a outubro de 2007, para a realização de trabalho de iniciação cientifica que deu origem a este artigo, foi utilizada a técnica de observação da forma como são conduzidas algumas audiências preliminares, bem como entrevistas com juízes titulares das varas cíveis e Juizado Especial da Comarca de Barretos e advogados da cidade de Barretos e Franca, ambas no Estado de São Paulo, e que atuam nas cidades da região, objetivando conhecer a realidade de tais operadores do direito na aplicação do disposto no artigo 331 do Código de Processo Civil, bem como, suas impressões sobre a efetividade das audiências preliminares, conforme suas experiências no cotidiano forense.

\footnotetext{
${ }^{33}$ ANDRIGHI, Fátima Nancy. Conciliação e realidade brasileira. Palestra proferida na V Jornada Brasileira de Direito Processual Civil, Foz do Iguaçu, 08/08/2003. Disponível em URL: <http://bdjur.stj.gov.br>. Acesso em 16/01/07.

${ }^{34}$ ANDRIGHI, Fátima Nancy. Id.

${ }^{35}$ WATANABE, Kazuo. Cultura da sentença e cultura da pacificação in Estudos em homenagem à Professora Ada Pelegrini Grinover, São Paulo, DPJ Ed., 2005.

${ }^{36}$ LIMA, Ari. Juizes e advogados devem ter capacidade de negociar. Revista Consultor Jurídico, 24 de setembro de 2007. Disponível em: <http://conjur.estadao.com.br/static/text/59764,1>. Acesso em: 10/10/2007.
} 
Quanto ao resultado das observações sobre a forma como são conduzidas as audiências preliminares, pôde-se notar que na maioria das vezes o juiz mostrou-se disposto a propor e tentar o acordo entre as partes. Em determinada vara cível, havia inclusive, durante a audiência, música ambiente, de forma a possibilitar uma atmosfera mais amena e propícia a um acordo, acalmando os ânimos das partes. Na maioria das vezes foi obtido o acordo, e quando não, ora motivado pelo desinteresse do advogado, ora o desinteresse vinha da própria parte litigante, que mesmo sendo orientada pelo advogado para celebração de acordo, mostrou-se irredutível. Neste caso específico, uma ação entre mãe e filha como adversárias, pode-se observar que por trás da demanda específica, havia um conflito muito maior, envolvendo sentimentos familiares, o que, com certeza, provocou o insucesso da tentativa de conciliação. Talvez, se houvesse ali o amparo de psicólogos ou assistentes sociais, o litígio poderia ter um desfecho diferente, e não somente para aquela demanda, mas também impedindo o surgimento de novos conflitos.

No tocante às entrevistas realizadas com os juízes, todos os entrevistados consideraram que a audiência preliminar do artigo 331 do Código de Processo Civil foi um avanço na legislação processual civil brasileira, principalmente se se considerar a situação anterior a ela, onde a tentativa de conciliação ocorria somente na audiência de instrução e julgamento, provocando toda movimentação da máquina do judiciário, sendo que às vezes era obtido o acordo, desperdiçando-se a atividade probatória das partes, tempo e dinheiro.

Também foi colocada a questão da importância de qualquer audiência que tenha a finalidade de obtenção de acordo entre as partes, pois essa é a melhor forma de solucionar os conflitos, pois que resolve definitivamente não só a causa objetiva, mas previne conflitos futuros.

Em relação à inserção do parágrafo $3^{\circ}$ ao artigo 331, tornando a audiência preliminar de certa forma facultativa, houve algumas divergências de opiniões. Para a maioria, a inovação foi de suma importância, pois que impede a realização de audiências onde é impossível a transação, sendo citada a questão dos entes públicos que estão impossibilitados de transigir e, também, quando desde o início da causa é possível detectar a improvável obtenção de acordo. Essa facultatividade proporciona exatamente o não entulhamento das pautas, pois não se marca uma audiência onde sua principal finalidade não será atingida.

É neste ponto que ocorreu a discordância, pois um dos juízes considera que é exatamente essa a oportunidade onde se deveria tentar a conciliação, pois existe aí um conflito intenso entre as partes e conciliá-las evitaria a instauração de novos processos no futuro. Para ele, o entulhamento ocorre exatamente por não haver nenhum tipo de conseqüência para o não 
comparecimento das partes quando designada a audiência preliminar, como ocorre, por exemplo, nos Juizados Especiais, onde o não comparecimento do autor acarreta a extinção do processo e sua condenação nas custas processuais, e o não comparecimento do réu, provoca a revelia.

Como um obstáculo à obtenção de acordos durante a audiência, foi citado o desconforto muitas vezes gerado entre as partes e seus advogados em relação aos honorários advocatícios no caso de se realizar o acordo. Comentou-se que isso gera um certo "clima" durante a audiência.

Todos os entrevistados mencionaram sobre os Setores de Conciliação instalados em quase todas as comarcas do Estado de São Paulo. Para eles existe uma efetividade muito maior, pois não há custo para as partes, não é obrigatória a presença de advogado, e pode-se obter a solução do conflito antes mesmo de se dar início a um processo judicial, embora também seja possível o acesso aos Setores de Conciliação mesmo com o processo já instaurado e em qualquer fase do procedimento. O índice de acordos extra-judiciais chega a $70 \%$ dos casos.

Entre os advogados entrevistados, não houve grande consenso de opiniões. Para $42 \%$ deles, a audiência preliminar veio para agilizar o processo, sendo o principal caminho para a resolução dos problemas. Não concordam quando se questiona sobre o insucesso das audiências de conciliação. Acreditam que ela tem produzido resultados positivos sim, baseados em sua experiência cotidiana, onde obtêm elevados índices de acordo nos processos em que atuam. Dentre as mudanças sugeridas e os problemas apontados está a questão do envolvimento dos operadores do direito - juízes e advogados - bem como das partes que muitas vezes não estão dispostas a tentar um acordo. Colocam que em muitos casos, o juiz não comparece à audiência preliminar, sendo esta realizada por estagiários ou serventuários, o que prejudica em muito a tentativa de acordo, pois a presença física do juiz impõe um comportamento diferente às partes. Observam ainda, que alguns juízes não conduzem as audiências preliminares visando a um acordo, não conversam com as partes e não esclarecem sobre as benesses de se encerrar o processo naquela oportunidade. Quanto aos advogados, existem aqueles que não orientam seus clientes para a possibilidade de acordo, e um dos obstáculos é exatamente a questão dos honorários advocatícios.

Para 28\% dos entrevistados, a audiência preliminar foi instituída com a intenção de se acelerar o feito, mas na prática não tem alcançado seu objetivo, transformando-se em um ato a mais, atrasando a busca do provimento jurisdicional final. Para o restante, a intenção do legislador reformista foi louvável, porém não obtém o resultado esperado em todos os casos. 
Depende muito da situação, para que se alcance maior êxito ou não. Foi colocado por um dos advogados que compartilham desta opinião, que deveria ser dado maior discricionariedade ao advogado, consultando-o sobre seu interesse para realização ou não da audiência do artigo 331, e não ficar relegada somente à faculdade do juiz em designá-la.

Todos os entrevistados concordam sobre a importância do papel do advogado no acompanhamento da parte em uma audiência preliminar, dando-lhe respaldo e resguardando seu direito. Neste aspecto, alguns dos advogados entrevistados orientam seus clientes sobre a possibilidade de se efetuar o acordo, mas deixam a decisão de realizá-lo ou não a cargo do próprio cliente. Outros, acreditam que é dever do advogado resolver rapidamente o problema do cliente, orientando-o sobre a importância de se realizar o acordo e encerrar o processo de maneira mais ágil, procurando demonstrar ao seu cliente as reais possibilidades da causa, não “iludindo-o" com eventuais procrastinações com o intento de se obter um resultado favorável, porém nem sempre possível.

Em agosto de 2006, a presidente do Conselho Nacional de Justiça - CNJ - ministra Ellen Gracie, promoveu o lançamento do “Movimento pela Conciliação”. Trata-se de uma grande mobilização nacional de iniciativa do CNJ em parceria com órgãos do Judiciário, Ordem dos Advogados do Brasil (OAB) e Conselho Nacional do Ministério Público (CNMP), além de associações de magistrados, entidades, universidades, escolas de magistratura e outros setores da sociedade civil.

O movimento, sob o slogan “Conciliar é legal”, tem como objetivo promover, através da cultura da conciliação, a mudança de comportamento dos agentes da Justiça, de todos os seus usuários, dos operadores de Direito e da sociedade. Além disso, pretende-se mudar comportamentos e induzir na sociedade a cultura de que um entendimento entre as partes e a conciliação é sempre o melhor caminho para o encerramento de um processo jurídico. Atualmente, a taxa de conciliação do país fica entre 30\% e 35\%, frente a um índice de cerca de $70 \%$ nos países desenvolvidos ${ }^{37}$.

Esse movimento, ao lado de outras ações, é também para a formação dos profissionais jurídicos nas técnicas e habilidades necessárias ao treinamento dos conciliadores que ajudarão os juízes. Nas mais de 800 faculdades de direito do Brasil, com raríssimas exceções, o aluno não tem disciplinas ligadas à conciliação ou a outros métodos alternativos de solução de conflitos, como a mediação e a arbitragem. O Movimento pela Conciliação não diminui a essencialidade dos profissionais jurídicos — juízes, advogados, procuradores, promotores,

37 Informações disponíveis em: ,http://www.stf.gov.br/portal/cms/verNoticiaDetalhe.asp? idConteudo= 67638\&caixaBusca $=\mathrm{N}>$. 
defensores públicos. Ao contrário: a conciliação sempre pode ser aprimorada com a participação de profissionais jurídicos, e eventual ilegalidade ou violação de direitos no procedimento conciliatório pode ser examinada pelo Judiciário. Todo o sistema judicial sai ganhando com a conciliação. Diminuir a demanda por sentenças é potencializar a atuação dos juízes sobre os casos que mais dependem da sua apreciação ${ }^{38}$.

Desde o início do movimento, o CNJ e seus parceiros deram início a uma série de atividades e medidas para consolidar o Movimento. Entre elas, está a edição da Recomendação número 8, que sugere aos tribunais o planejamento e a viabilização das atividades conciliatórias. O CNJ ofereceu ainda, ao longo do ano, cursos de formação de multiplicadores em conciliação, em todas as regiões do País. Os treinamentos formaram 200 pessoas em todo o País, que por sua vez formaram conciliadores em seus tribunais. Na Semana da Conciliação de 2006, foram realizadas 83.987 audiências em todo o país, e o índice de acordos chegou a 55,36\% ${ }^{39}$.

\section{Conclusão.}

Após análise de todo material coletado, bem como os resultados de pesquisas de campo efetuadas sobre o assunto, pôde-se concluir que a audiência preliminar do artigo 331 do Código de Processo Civil, é mais um instrumento colocado à disposição dos operadores do direito para que se promova uma prestação jurisdicional efetiva e célere, agilizando e encerrando rapidamente o processo.

Aqueles que alcançaram o real objetivo da norma, despojando-se da velha cultura da sentença e afastando sua formação acadêmica voltada para soluções contenciosas do conflito, estão obtendo resultados positivos e índices elevados de acordo nas audiências preliminares.

Para que esses índices se elevem cada vez mais e a cultura da pacificação se propague em nosso país, é preciso que haja uma mudança de mentalidade, principalmente por parte de juizes e advogados, aceitando a necessidade da sociedade moderna por técnicas mais ágeis de solução de seus problemas jurídicos. Dizemos que a mudança deve ocorrer principalmente por parte de juízes e advogados, pois são estes que orientam os litigantes e que estão à frente do processo, devendo sempre zelar pelo seu fim social e econômico.

\footnotetext{
38 FALCÃO, Joaquim. Movimento pela conciliação. Disponível em URL: <http://www.stf.gov.br/ arquivo/cms/conciliarConteudoTextual/anexo/artigo_02.pdf>.

39 Informações disponíveis em: <http://www.cnj.gov.br/ index.php? option=com_ content\&task= view\&id=3512\&Itemid=167> . Dados estatísticos sobre Semana da Conciliação disponíveis em: $<$ www.conciliar.cnj.gov.br>
} 
Nota-se que essa mudança começou a ocorrer, embora um pouco tardiamente, através da instalação dos Setores da Conciliação em quase todas as comarcas do Estado de São Paulo e dos mutirões de conciliação realizados em todo país, onde se observa elevados índices de acordo.

Para finalizar, utilizando-nos das palavras do ilustre processualista Humberto Theodoro Junior, "pensar-se em reformar a lei sem se preocupar com a reforma simultânea ou sucessiva dos agentes que irão operar as normas renovadas, chega a ser uma utopia, para não dizer uma temeridade" 40 .

\section{Referências Bibliográficas.}

ANDRIGHI, Fátima Nancy. O instituto da conciliação: a reforma processual. Publicação, 1994. Disponível em URL: <http://bdjur.stj.gov.br>. Acesso em 16/01/07.

Formas alternativas de solução de conflitos. Disponível em: <http://bdjur.stj.gov.br>. Acesso em: 15/09/2007.

. Conciliação e realidade brasileira. Palestra proferida na V Jornada Brasileira de Direito Processual Civil, Foz do Iguaçu, 08/08/2003. Disponível em URL: $<$ http://bdjur.stj.gov.br>. Acesso em 16/01/07.

BARBI, Celso Agrícola. O papel da conciliação como meio de evitar o processo e de resolver conflitos. RePro 39/121.

CARNEIRO, Athos Gusmão. Audiência de instrução e julgamento e audiências preliminares, $13^{\mathrm{a}}$ ed., Rio de Janeiro: Forense, 2007.

CENEVIVA, Walter. Conciliação no processo civil brasileiro in Reforma do código de processo civil, coord. Sálvio de Figueiredo Teixiera. Ed Saraiva: São Paulo, 1996.

CRUZ E TUCCI, José Rogério. Horizontes da nova audiência preliminar, Revista Forense, vol 370, 2003.

DALL'AGNOL JUNIOR, Antonio Janyr. Sobre a audiência de conciliação. Curitiba: GenesisPro, n. 2, maio/ago. 1996.

DINAMARCO, Candido Rangel. A reforma do código de processo civil, $5^{\mathrm{a}}$ ed, Malheiros: São Paulo, 2001.

A reforma da reforma, $4^{\mathrm{a}}$ ed., São Paulo: Malheiros, 2002;

FALCÃO, Joaquim. Movimento pela conciliação. Disponível em URL: <http://www.stf.gov.br/ arquivo/cms/conciliarConteudoTextual/anexo/artigo_02.pdf>.

${ }^{40}$ THEODORO JUNIOR, Humberto. Celeridade e efetividade da prestação jurisdicional. Revista TrinoLex. com, ano 1, n. 2, jan/fev 2005, pag 31. 
FREITAS, Vladimir Passos de. Judiciário busca alternativas para combater morosidade. Revista Consultor Jurídico, 22 de agosto de 2007. Disponível em: $<$ http://conjur.estadao.com.br/static/text/58759,1. Acesso em: 15/09/2007.

GAJARDONI. Fernando da Fonseca. Técnicas de aceleração do processo. São Paulo: Lemos e Cruz, 2003.

GRUNWALD, Astried Brettas. A mediação como forma efetiva de pacificação social no Estado Democrático de Direito . Jus Navigandi, Teresina, ano 8, n. 289, 22 abr. 2004. Disponível em: <http://jus2.uol.com.br/doutrina/texto.asp?id=5117>. Acesso em: 15/09/2007.

KEPPEN, Luiz Fernando Tomaso. Aspectos da reforma do código de processo civil, RePro $84 / 42$.

LIMA, Ari. Juizes e advogados devem ter capacidade de negociar. Revista Consultor Jurídico, 24 de setembro de 2007. Disponível em: <http://conjur.estadao.com.br/static/text/59764,1>. Acesso em: 10/10/2007.

MATSUURA, Lílian. Depois de 10 anos, lei de arbitragem começa a ter efeito. Revista Consultor Jurídico, 7 de julho de 2007. Disponível em: $<$ http://conjur.estadao.com.br/static/text/57342,1>. Acesso em 15/08/2007.

MOREIRA, José Carlos Barbosa. Vicissitudes da audiência preliminar. Revista Forense, vol 374, 2004.

Saneamento do processo e audiência preliminar, RePro 40/109.

NACARATO, Gabriela. Arbitragem como um dos métodos alternativos para solução de conflitos. Disponível em: <http://www.epm.sp.gov.br/SiteEPM/Artigos/146.htm>. Acesso em 10/10/2007.

NERY JUNIOR, Nelson. Audiência preliminar e saneamento do processo, in Reforma do Código de Processo Civil, coord. Sálvio de Figueiredo Teixeira, Saraiva: São Paulo, 1996.

SILVA, João Carlos Almeida. Mediação. Disponível em: http://www.webartigos.com/articles/2171/1/MEDIAÇÃO/Pagina1.html. Acesso em: 15/09/2007.

SIQUEIRA, Cleanto Guimarães. As novíssimas alterações do código de processo civil, Rio de Janeiro: Forense, $1^{\text {a }}$ ed., 2003.

SOUSA, Lilia Almeida. A utilização da mediação de conflitos no processo judicial. Jus Navegandi, Teresina, ano 9, n. 568, 26 jan. 2005. Disponível em: <http://jus2.uol.com.br/doutrina/texto.asp?id=6199>. Acesso em: 15/09/2007.

STAMFORD, Artur. Etnometodologia da conciliação judicial: uma análise do cotidiano forense. Disponível em URL: http://www.conpedi.org/manaus/arquivos/Anais/Artur\%20Stamford.pdf. Acesso em $14 / 05 / 2007$. 
THEODORO JUNIOR, Humberto. Celeridade e efetividade da prestação jurisdicional. Revista TrinoLex. com, ano 1, n. 2, jan/fev 2005.

Curso de direito processual civil, vol I, 42ª ed., Rio de Janeiro: Forense, 2005.

TUCCI, Rogério Lauria. A nova fase saneadora do processo civil brasileiro, in Reforma do Código de processo civil, coord. Sálvio de Figueiredo Teixeira, São Paulo: Saraiva, 1996.

WAMBIER, Luiz Rodrigues. A nova audiência preliminar (art. 331 do CPC) RePro 80/30.

WAMBIER, Luiz Rodrigues. ALVIM WAMBIER, Teresa Arruda. Breves comentários à $2^{a}$ fase da reforma do código de processo civil, $2^{\circ}$ ed., São Paulo: Revista dos Tribunais, 2002.

WATANABE, Kazuo. Cultura da sentença e cultura da pacificação in Estudos em homenagem à Professora Ada Pelegrini Grinover, São Paulo, DPJ Ed., 2005. 